\title{
Traditional Rebel, Ecological Singer
}

\section{- On Lawrence's poem: The subversion of the traditional image of "Snake" of the western literature}

\author{
Wangyan $\mathrm{Ma}^{1, \mathrm{a}}$, Peng $\mathrm{Yu}^{2, \mathrm{~b}}$ \\ ${ }^{1}$ School of Foreign Stuides, Anhui Sanlian University, Hefei 230601, China \\ ${ }^{2}$ School of Foreign Stuides, Anhui Sanlian University, Hefei 230601, China \\ a jerrywangyan@163.com , b42123244@qq.com
}

Key words: Lawrence; snake; Id; superego

\begin{abstract}
The snake in the traditional western literature is the devil's pronoun; in most of the western classical literature works the snake is equivalent to Satan. However, Laurence's poetry "snake" completely subvert the negative image of the snake. From the perspective of spiritual analysis and ecological literature, Lawrence created the "snake" active, noble, harmless, and echo the "Id" both inside and outside of the poet, while dislike for snakes of "superego" reveals "human education" to oppress human nature. The poet's confession shows that the snake has won the respect of the poet and the poet's inner world, which completely denies the image of the snake in the western literature.
\end{abstract}

\section{Introduction}

As an ancient culture imagery in early human society snake can be traced in different forms in various human activities. Regarding snake as a totem is a worldwide cultural phenomenon. Western culture is rooted in two "Greek" culture-the Greco-Roman culture and the Hebrew culture, with which a variety of snake-related stories and legends are permeated. With the image of half man and half snake monster-Lamia in Ancient Greek mythology, and of the snake in the Garden of Eden in the Hebrew "Bible", snake has been synonymous with greed, temptation, the devil and the like.

The two Western culture has a profound influence. Most Western classical literary allusions and images are drawn from both. As the writer continues the creation, a negative image of snake in Western Literature is basically established. Meanwhile, there are some few examples with activelyportrayed snakes: British writer David Lawrence's narrative poem "snake" is one of them. Lawrence had created more or less a thousand poems, whose poetry can be basically divided into 
early, middle and late stages. Lawrence’s early poems are mostly autobiographical; in the middle stage his poems displays his love of nature; his late poetry expresses his views on death and rebirth. "Bird • Beast • Flower" is one of the masterpieces of his poetry, whose theme is the praise of the nature, and "snake" is one of the best in the anthology. Through thorough reading, from the point of psychoanalysis and ecological literature this paper attempt to interpret the poem "snake", analyze how Lawrence create the active image of snake, and how this poem subverts the Western traditional snake image and try to analyze its effect and meaning.

\section{The Poet- "I" indulgence with snake contrary to traditional image of snake}

Narrative poem "snake" at the beginning exposes readers a clear account of the basic elements of the story such as time, the role and place, etc.. In the first paragraph, the author writes: “A snake creep my sink, on a hot day, I was hot while wearing pajamas, went to drinking water.” It’s obvious that snake is the subject of the first sentence while "I" appear in the second sentence, in the form of parenthesis implying the importance of the snake more than "me." Through stressing waiting, Lawrence gives the reason - because the snake arrived at the sink first, which impresses the readers the feeling I should wait. But without fear, the author described snake in details: "He climbed out through a crack in the dark walls, towed tawny soft belly, came to the edge of the stone sink, resting at the bottom of the stone of the throat, where, little by little water from a faucet dripping, a pool of shallow water, with his straight mouth sucking water through straight gums, gently shed loose long body, quietly. " The third section contains a lot of words used in the "s" sound, indicating a "hissing" sound very similar to the snake, giving the feeling of being there, but the "I" do not feel afraid, but vigil at the side enchanted admiring the intruder. Then Lawrence expressed the reason why "I" respected snake instead of fear:. "snake is ahead of me, just like a person, so "I” must wait.” In this case, compared with the first impression, Lawrence emphasizes prominently that "I" am the later." Thus, from the perspective of Lawrence, the position of the snake values more than me. Snake is my distinguished guests. In the fifth paragraph, the "I" observe the "guest" more carefully: "He looked up from the sink, like an animal, dull staring at me like an animal to drink, gently pop the double fork tongue from the mouth, he thought for a moment, then leaned over to drink a little ...

Obviously, "my" attitude towards snake is completely unbiased and without any animosity 
affection. On the one hand, the description of the snake in the original text is used the anthropomorphic approach for example the author used "lips" to describe the mouth of the snake and used "muse" to portray snake's contemplation as an elegant guest. On the other, the author emphasized snake’s harmlessness like other livestock, "staring at me like an animal to drink. The very serenity reflects the calmness of the mood without any slightest fear.

According to Freud's psychoanalytic theory, the "I" am an innate animal instinct at the bottom of the heart and it is confusing, irrational, and acting only in accordance with the "pleasure principle". The encounter of the "I" with the snake displays "my" love and appreciation between the lines. This affection is completely out of instinctive appreciation of the good things without any rational domination, exhibiting the state of the "I". For "I", the snake on the road is not only different from the traditional negative images of snakes, but also from our traditional concept of a snake with a strong attack. In essence, the "I" am the same as the common livestock, but as a certain kind of snake on purely biological sense. From the perspective of the biology, if without attack or in the state of prey, snakes do not usually attack something else. Human beings can coexist with the most animals peacefully, why do not snakes? Why should human beings avoid snake without purpose? From the encounter between "I" and the snake point of view, the "I" will treat the snake biologically, consider the snake as an honorable guest and thus initiate appreciation of beauty of snake without any restraint of the traditional secular ideas. Here, the poet highlights the relative calmness between the "I" with the snake, showing a better picture of coexistence. The attitude of the "I" obsession with the snake is in conflict with the traditional literary image.

In western traditional literature the image of a snake is basically negative, although there are a few works which transform the traditional image of a snake, like Keats' description of the snake lady Ramil who was portrayed as elegant lady with a heart and a consistent look, as incarnate of romantic, tolerating the piercing pain into human form in order to chase love. Keats' poem subverts the traditional readers' impression on snake that snake is evil witch while Keats depicts snake as a goddess of positive energy, the innocent victims, and ultimately the tragic ending exposes the result of indifferent ration repressing passion and desire, which greatly arouses the readers' compassion in accordance with the portray of the tragic characters in the western literature. The portray of the traditional characters in Western poetry has a tendency to transcend phenomenon, sensual world, metaphysical body mostly to explore metaphysical issues indicating philosophical sentiment to 
human life, society, nature . The seemingly negative image of lady snake shaped by Keats is not true: the aesthetic experience stimulates the readers while the passion gradually subsides with the familiarity to the content of the plot. The rational thinking outweighs the form appreciation: the purpose of the positive image of the lady snake is to produce the readers' rational perception to make them realize the confusion of lady snake even the danger. Simultaneously it can result in the rational restraint, impresses the readers' ration and makes a rational exaltation come true. So Keats' positive image of lady snake ultimately serves as the theme of a negative image of snake in the literary tradition.

However, "I", snake and "snake” portrayal in Lawrence Poetry is not the case, not only from the positive portrayal of the snake. And in above poem, the "I" appreciate the snake to give readers aesthetic pleasure of the "tasting type" . The familiarity with the contents of the plot highlights the aesthetic appreciation and rational thinking is second to none. As reading further, readers experience the detailed appreciation and indulgence. Snake impresses the readers' emotions and addiction, signifying the harmony between the "I" and a snake, man and nature.

\section{The repression of Poet's "self" "superego" to "I" reveals the struggle between the poet and literary tradition}

With respect to the "I", the "self" is the split from the "I" due to the reality and gradually cultivated knowledge. "self" acts as the contact and arbiter, and supervises "I" activities under the "superego" guidance, representing the well-known ration or right judgment in accordance with the "reality principle”. In the sixth section, the happiness of appreciating snake suspended. Lawrence wrote: "I made a sound because of common sense, said to me: he must be killed, because in Sicily, black snakes are innocent, golden snakes are poisonous.” In reality, common sense is the voice of reason on behalf of the poet's "self”, that is, the poet rational side. The enjoyment of "I" addiction to snake halts suddenly. The poet's "self” attempts to suppress poet's "I" in order to enhance the reason of "self", giving a reasonable explanation from the scientific point of view: because in Sicily, black snakes are innocent, golden snakes are poisonous. The sound warns "I", trying to pull "I" back from the enjoyment to reality. Here, the self "reality principle” suspends "pleasure principle.”

From the perspective of the style of the writing, the five segments are rendered respect, love, and appreciation of "I"for snakes, and successfully make readers enter into the harmonious picture 
between man and snake. In contrast, there are just four lines to describe the repression of "self" to "I" in the sixth part. This shift, whether it is from the feeling of snakes or from readers' acceptance, is unexpected, and powerless. Since the command issued by the "self" and the scientific explanations are inadequate, in the seventh part, the "superego," the voice of solidarity supports "self": the voice inside me said, / if you are a man, / you should grab sticks, /hit it / kill it. In this case, these voices call "I" a man. The word "Man" enhances "I" up to the level of society, see "I" as a human society, in opposition to the alien snake and persuade me with the principles of society. "Superego" and "self" are different in that "Superego" represents the punishment and regulation of social norms and moral individual, striving to improve defenders. "Superego" has been described as an advanced objective of human life. On the other hand, the adoption of "you" exposes this sound, signifying the opposition to the poet's "I". The poet emphasizes the sound is the internal voice which is against "I". The different person obviously stresses the different attitude to snakes of "Self” "Superego" and “I”.

With these two heavy repression, the poet’s "I" began to reflect: But I must admit that I liked him very much, and I am pleased to see him quietly come down and visit. . . . . Whether out of weakness, I dare not kill him? / or because of metamorphosis, I am eager to talk to him? / or due to humble, I feel so glory? / I am very glory. Readers experience the "I" indecision under repression and persuasion of the "ego" and "superego". On the one hand, by nature, "I" can not repress love of snakes, and on the other hand, in terms of rational judgment and social ethics of snakes "I" begin to produce fear. But after these reflection and hesitation, "I" like snake slightly better, adhering to the love of snakes, and also feel very proud. A sentimental favorite overcomes the constraints of reason, highlighting the poet's heart and contrary to the traditional concept of snake.

\section{The change of poet's attitude and behavior of treating snake demonstrates the presence of a strong literary tradition}

However, living in the real world, people are bound by the rules of social behavior. And the enjoyment in nature in conflict with reality, traditional rules will inevitably be subject to a certain extent. Therefore, to compete with the literary tradition, the continuation of this joy faces a big resistance. Before poet calms, from the voice of "ego" and "superego" launched a new offensive to the poet: "If you are not afraid, you have to put him to death!.” In the face of a new round, "I” am 
gradually defeated to accept the voice of reason and persuasion and confess fear for snake. Indeed, I am afraid, very afraid, even so, I feel glory. It can be seen that although the "I” approve persuasion of the voice of reason that "I" should not be so fond of snakes, should be like everyone else, considering that the snake is an ominous thing and should see aloof. But at the same time, "My" excuse and insistence also present to readers: Because he's from the dark secret door to get out of the earth, coming to seek my feeling of hospitality. "I" also continue to adhere to its position to defend actions, and further contend with the traditional statute. On the one hand the "I" try to separate snake with traditional dark, invisible world, simply see a snake from a biological sense, having nothing to do with evil. Poet stresses that snakes coming out from the dark door does not necessarily represent the dark, evil things. On the other hand, the "I" continue to adhere to the appreciation of snakes: he drank enough, head up and trance, like a drunk in the air, shaking his tongue like that night fork, licking his lips, turning a blind eye like God and looking around the world. The snake out of the darkness is depicted more dignified, calm demeanor like God overlooking the world. Then, the "I" attitude worsened and attacked the snake: when he put head in that horrible cave, when he slowly stopped. relaxed shoulders, and then continued, when he withdrew into that terrible black hole, calmly into darkness, slowly dragged himself into a terror. The revolt against this behavior occupied my mind and body, but he ignored me, in the end the snake drilled into a terrible cave. I looked around, put down the pitcher, picked up the heavy wood, snapped pound sink. Under repeated persuasion of rational voice and my careful observation, the snake entered eventually into the dark door, that beckons of dark unknown world indicating the hell and evil. "I" am immediately clear. Emotion is occupied by ration. At present, "I" realize that since the snake is coming out of the darkness, he represents the evil. In the poet's subconsciousness, the beauty of the snake still can not compete with the dark world and the fear of hell. Still the traditional values roots deeply in the poet's heart.

\section{Poet's repentance and subversion of literary tradition}

The poet's attitude of snakes has completely transformed from respect to attack. Whether poet is bound by traditional statute, he hated snakes. The reality is not so. Superficially it seems that "I" am impressed by "ego" and "superego" to shift attitude while in fact the details reveals it is not the case. First, the "I" separate the snake with dark world: the snake is a simply biological snake 
without any contact with the world of darkness; 。 Second, the aim of the "I" attacking is the dark world, not the snake itself. The poet emphasized that he threw the wood to the pound sink not a snake. "I" feel that this behavior is upset, after all, the snake did not initiate the attack. This "Superego" behavior depends entirely on the "voice of human education.” This makes the "I” feel hatred for the own subconscious behavior because it was manipulated by "human education” . I felt annoyed;I felt my actions are rude, mean; I hate myself, hate the sound of human education. Jung's "shadow" theory believes that in order to avoid resistance of shame, anxiety, guilt,caused by moral, self-consciousness is more willing to project the dark horrible personality to others. In order to find a reasonable explanation for"superego", "I” give the poet's heart "snake” the existent reason. Thus, the poet thinks of Coleridge's poem "old sailor”, although the old sailor is eventually forgiven, the albatross he shot can not revive, even in the legendary story. "I" am aware of insignificance and humble, because a snake is like an exiled emperor,once again that the status of"snake" is much higher than the "I". The snake is in the eyes of the poet as a complementary force to a human nature and recognition of "I" always subjecting to discrimination and repression. Western literary tradition holds that God is in control of the Garden of Eden, and Satan is the corresponding ruler of the underworld. In the "Bible" Satan is parasitic in the snake. Originally the snake was lofty in all things God made and Satan is matched. “The voice of education” refers to the cultural origin inherited from the "Bible": snakes are evil; the source of the temptation of human sin; everyone can be very vocal. However, in the last part, the poet subverts the literary traditional dislike of snakes, approving the snake in the heart, so snake is finally accepted and crowned, because snake is no longer the animal from the traditional sense, which is derived from a naturally wild animal. Animal instinct gives it sensitivity, elegance, serenity and calm. It is snakes that poet respects with the poet's permission into the heart and endows the snake with its vitality and courage.

\section{Conclusion}

In a sense, the creation of positive image of a snake is a compliment in order to meet the author's purpose: Keats described the snake both good and evil; Coleridge even depicted a snake as a must to rescue the soul. Lawrence did not create snake's positive image overall, but neutrally and objectively described snake to convex inner conflict between the poet, "I”, "self” and "superego". Through the struggle and contradiction, and final repentance for snake, poet expresses love and 
respect thereby subverting the "dark" image of snake in the western literary tradition and giving a completely new life to the image of the snake.

\section{References}

[1] Hong Chen. On Lawrence poetry "snake" and "Snake” images [J] Foreign Literature Research. (2007) 130-139.

[2] Wenmei Chang. The Origin of Lawrence "snake” image[J]. Author. (2012)107-108.

[3] Bai Fei. World Poetry Library [M]. Hua Cheng Publishing House, 1994.

[4] Xinguo Ma. Western Literary History [M]. Higher Education Press. 2008.

[5] Yunnan Zi. On the ecological consciousness in Lawrence "snake” [J] Hengyang Normal University. (2010) 136-139. 